\title{
Flow characteristics of individual lot stormwater detention
}

\author{
Johnny Ong King Ngu*, Darrien Yau Seng Mah and Charles Hin Joo Bong \\ Department of Civil Engineering, Universiti Malaysia Sarawak (UNIMAS), Kota Samarahan 94300, Sarawak, Malaysia \\ *Corresponding author. E-mail: johnnyngu91@gmail.com
}

\begin{abstract}
In this paper the flow characteristics of stormwater are analyzed as it travels from a roof gutter down-pipe and the turbulent flow generated on entering an individual lot on-site stormwater detention (OSD) unit beneath a residential carport. Comparison was made between a full-scale model and computational fluid dynamic (CFD) simulations to determine the flow characteristics. These modular tanks with multi-unit chambers can capture the roof run-off from a 15-minute, 10-year return period storm. The results from the physical and CFD models matched well, suggesting that turbulent flow occurs when stormwater is directed to an individual lot stormwater detention tank. However, turbulence in the OSD was concentrated around the inlet, after which the pattern changed from turbulent to laminar flow. This work implies that the use of modular underground storage tanks is practical for managing stormwater from a roof.
\end{abstract}

Key words: computational fluid dynamics, on-site stormwater detention, turbulent flow

\section{$\overline{\text { INTRODUCTION }}$}

Impervious areas such as parking lots, paved streets, and building roofs produce stormwater discharges during rainfall events. Uncontrolled runoff can cause significant environmental problems (Mah et al. 2016). One control method for stormwater discharges is by on-site stormwater detention (OSD). Stormwater runoff can be slowed and the peak discharge reduced using OSD, which is expected to solve flash flood problems (Haberland et al. 2012; Mah et al. 2014). Such a system has been widely applied in Sydney, Australia, since 1991; detention storage is provided for stormwater on project development sites to limit rates of runoff (O'Loughlin et al. 1995). In previous OSD studies, centralized, large-scale control structures were used, such as wet ponds (Chang et al. 2013; Ahmad et al. 2014) and detention basins (Vorogushyn et al. 2012). In spite of that, the availability of empty land is decreasing in urban areas.

Because of the above, locally distributed control structures are gaining in importance as means of catering for physiographic and urban development characteristics (Hamel et al. 2013). There is extensive literature on best management practice covering various measures (Baker \& Doneux 2012; Reynolds et al. 2012; Ritchie 2014) but there is no mention of the use of carports. This arises from different living styles.

In Malaysia, in general, a carport has become a necessity of house ownership. A large carport is a common strategy used by developers to attract buyers. Making use of the area provided by a carport, enables stormwater from the roof to be held in a detention tank beneath it. At the lot - i.e., single dwelling - scale, stormwater control measures have been reported as effective in reducing stormwater runoff (Loperfido et al. 2014). The cumulative effect is great when combining the small effects of individual lots.

One issue that needs to be dealt with before using OSD in such a way is the flow characteristics of stormwater directed to an OSD beneath a carport. High runoff rates can be generated from roofs 